\title{
The use of a mirror reduces isolation stress in horses being transported by trailer
}

\author{
Rachel Kay ${ }^{1 *}$ and Carol Hall ${ }^{1}$
}

\author{
${ }^{1}$ School of Animal, Rural and Environmental Sciences \\ Nottingham Trent University \\ Brackenhurst Campus \\ Southwell
}

Nottinghamshire

NG25 0QF

\begin{abstract}
Horse trailers are a common form of transportation for horses and ponies and often require the animal to travel alone or with a single companion. The current study investigated the effect of transporting horses alone, in company or with an acrylic safety mirror (measuring $81 \times 61.5 \mathrm{~cm}$ ) that provided surrogate companionship. The behavioural and physiological responses of twelve mature horses during a 30-minute journey by trailer under the three treatments were compared. Behaviour (vocalisation, eating, head-tossing, pawing, and head turning) was recorded. In order to assess circulatory changes that occur as part of the response to transport, heart rate $(\mathrm{HR})$, rectal $\left(\mathrm{T}_{\mathrm{r}}\right)$ and ear-pinna $\left(\mathrm{T}_{\mathrm{p}}\right)$ temperatures were recorded. When travelling with a live companion significantly less time was spent vocalising $(p<0.001)$, head turning $(p<0.001)$, head-tossing $(p<0.01)$ and pawing $(p<0.01)$; eating behaviour increased $(p<0.05)$. Physiological responses (increases in HR and $\mathrm{T}_{\mathrm{r}}$ and decreases in $\mathrm{T}_{\mathrm{p}}$ ) were also significantly reduced when travelling with a live companion $(\mathrm{p}<0.01)$. Travelling with the mirror did not significantly affect physiological responses compared with travelling alone, but the rise in $T_{r}$ and fall in $T_{p}$ was reduced $(p=0.052$ and $\mathrm{p}=0.051$ respectively) and can be considered a trend. When travelling with a mirror significantly less time was spent turning the head $(\mathrm{p}<0.01)$, vocalising $(\mathrm{p}<0.05)$ and head tossing $(\mathrm{p}<0.05)$; eating behaviour increased $(\mathrm{p}<0.05)$. The only significant difference between travelling with a live
\end{abstract}


companion and a mirror was that the time spent turning the head round was less with a live companion $(\mathrm{p}<0.05)$. The provision of surrogate companionship in the form of a mirror was found to be preferable to travelling alone, but where possible a live companion is recommended. Isolation during transportation was found to suppress feeding behaviour. Although peripheral blood flow $\left(T_{p}\right)$ has been used to assess transport stress in other species it has not previously been used in the horse. Further evaluation of this non-invasive measure is now required.

*Corresponding author. E-mail address: rachel.kay@ntu.ac.uk

Keywords: Horse; Isolation; Transport; Trailer; Mirror; Stress.

\section{Introduction}

The transport of horses by road results in the animal being subjected to a number of potential stressors. As a result, behavioural problems are often associated with this activity. In a survey of trailering problems it was found that $53.4 \%$ related to loading and $51.5 \%$ to travelling (Lee and Houpt, 2001). While problems associated with loading may be inconvenient and a potential safety hazard, those occurring in transit have long been linked with reductions in performance, health and welfare (Cregier, 1982; Leadon, 1995; Friend, 2001). Changes in body posture and elevated heart rates were recorded in horses during a 25-minute journey by road (Waran and Cuddeford, 1995). In addition to the physical effort required to maintain balance during transportation, the horse is required to adapt to a number of other environmental stressors. These include variations in temperature, humidity, air quality, vibration and food and water restrictions (Cregier, 1982). On longer journeys such factors may compromise health (Traub-Dargatz et al., 1988; Oikawa et al., 1995).

Isolation is a source of stress in herd species such as the horse. It has been shown to result in a number of physiological and behavioural responses in non-transport situations. Behavioural signs of agitation in response to isolation have included erratic movements, pawing, turning round 
(attempting to join other horses) and vocalisation (Alexander et al., 1988; Jezierski and Gorecka, 1999; 2000). In addition, isolation has been shown to reduce the time that horses spend eating (Sweeting et al., 1985; Houpt and Houpt, 1992; Strand et al., 2002). Physiological signs of isolation stress such as hyperventilation and sweating (Alexander et al., 1988) and significant increases in heart rate (Jezierski and Gorecka, 1999; 2000) have also been recorded. The consequences of transporting horses alone require further investigation.

The response of sheep (Ovis aries) to isolation from con-specifics has been shown to be similar to that of the horse. In particular, visual isolation has been found to cause both increases in heart rate and changes in behaviour (Baldock and Sibly, 1990). Such increases in heart rate are associated with redistribution of blood during the "fight or flight" response and are a sign of acute stress. However, during transportation an elevated heart rate has been shown to relate to balance preservation (Giovagnoli et al., 2002) and may limit its use as a measure of isolation stress in this case.

The acute stress response results in vasoconstriction in non-critical organs and vasodilation in critical organs. Recent studies have recorded a significant decrease in ear-pinna temperature, concurrent with an increase in core body temperature in sheep exposed to a stressor. Results confirm that changes in ear-pinna temperature could be used as a sensitive, non-invasive measure of activation of the 'flight' reaction in prey species (Ingram et al., 2002; Lowe et al., 2005). This measure has not previously been used in the horse.

The creation of surrogate companionship by the use of a stable mirror can reduce the incidence of stereotypical behaviour in the horse (McAfee et al., 2002; Mills and Davenport, 2002). Mirrors have also been shown to reduce the stress response of cattle (Piller et al., 1999) and sheep (Parrott et al., 1988) to isolation. Although isolation has been identified as a possible source of stress during transportation (Waran and Cuddeford, 1995) no comparison has been made between the responses of horses travelling alone, with a companion, or with a mirror that could act as a surrogate companion. Following the success of the stable mirror a similar product for use during 
transportation is now commercially available, but no published studies have evaluated the efficacy of these products under controlled conditions.

The aim of this study was to compare behavioural and physiological responses of horses travelling alone, with a live companion or with a mirror. In addition to the standard measure of heart rate, changes in rectal and ear-pinna temperature were also recorded. If consistent, these measures would provide an alternative non-invasive method of assessing acute stress in the horse.

\section{Materials and methods}

\subsection{Subjects}

The animals used in the study consisted of 12 mature leisure horses and ponies of various types: 5 mares and 7 geldings. They were aged between 8 and 22 years, with a mean age of 15 years. Their heights ranged from 112 to $175 \mathrm{~cm}$ with a mean height of $159 \mathrm{~cm}$. None of the animals used in the study were transported regularly (Table 1) and at the time of the experiment, lived at grass together as a social group.

Table 1 - Age, sex, breed and height of experimental subjects, and information provided by owners regarding incidence of travel during previous twelve months.

\begin{tabular}{llllll}
\hline Horse & Age & Sex & Breed & Height (Hands) & Transport in prev. 12 mths \\
\hline 1 & 19 & M & ID X TB & 16.1 & No \\
2 & 16 & M & ID & 17.1 & No \\
3 & 22 & G & Connemara x Arab & 15.1 & No \\
4 & 21 & G & TB & 16.1 & No \\
5 & 22 & G & TB & 16.1 & No \\
6 & 8 & M & Warmblood x TB & 17 & Twice (to stud) \\
7 & 15 & G & Welsh A & 11 & No \\
8 & 20 & M & TB & 16 & No \\
9 & 11 & G & New Forest & 13.2 & No \\
10 & 9 & G & TB x $?$ & 16.2 & Twice (to vet) \\
11 & 10 & M & TB & 16.1 & No \\
12 & 8 & G & ID x TB & 16.2 & Once (to vet) \\
\hline
\end{tabular}




\subsection{Test apparatus and design}

A Bahill Sportsman two-horse trailer (extra height version) was used to transport the horses, towed by a Landrover Discovery. Prior to the main experiment an ethogram of behaviours was devised (Table 2), and a pilot study carried out to test recording equipment. During both the pilot study and main experiment the video recorder (Samsung Digital Video Recorder) was fixed to the central partition pole at the rear of the trailed and operated by a remote control handset. Prior to the main experiment each horse was familiarised with the loading and unloading procedure, exposed to the safety mirror (identical to travel mirror) fixed onto the stable wall for two periods of at least 3 hours, and accustomed to travel equipment (boots and tail guard).

Table 2: Ethogram giving a definition of each behavioural state observed and recorded when horses were transported.

\begin{tabular}{ll}
\hline Behavioural state & Description of behaviour \\
\hline Vocalisation & Includes neighs, whinnies, snorts and squeals \\
Head turning & Head turned either to right or left so white of eye seen \\
Feeding & Hay removed from haynet (including time spent chewing) \\
Pawing & Raising a front leg and scraping it forwards and backwards over the floor \\
Head tossing & Wringing of the head and neck, and/or throwing the head up and down \\
\hline
\end{tabular}

All horses were each transported three times, once in one of three conditions: alone; alone but with a mirror fitted to the left side of the trailer opposite the test horse's head; or with a companion horse. The mirror used was an acrylic safety mirror measuring $81 \times 61.5 \mathrm{~cm}$, mounted on medium density fibre board (a man made material used as an alternative to wood). This was hooked onto the inside of the trailer after the test horse had been loaded. Throughout the study the test horses travelled on the right side of the trailer. The same companion horse was used throughout the study and was loaded onto the trailer once the test horse was installed. A small hay-net was placed inside 
the trailer prior to the test horse being loaded. Figure 1 shows the position of the test horse in the trailer, the hay-net and the mirror.

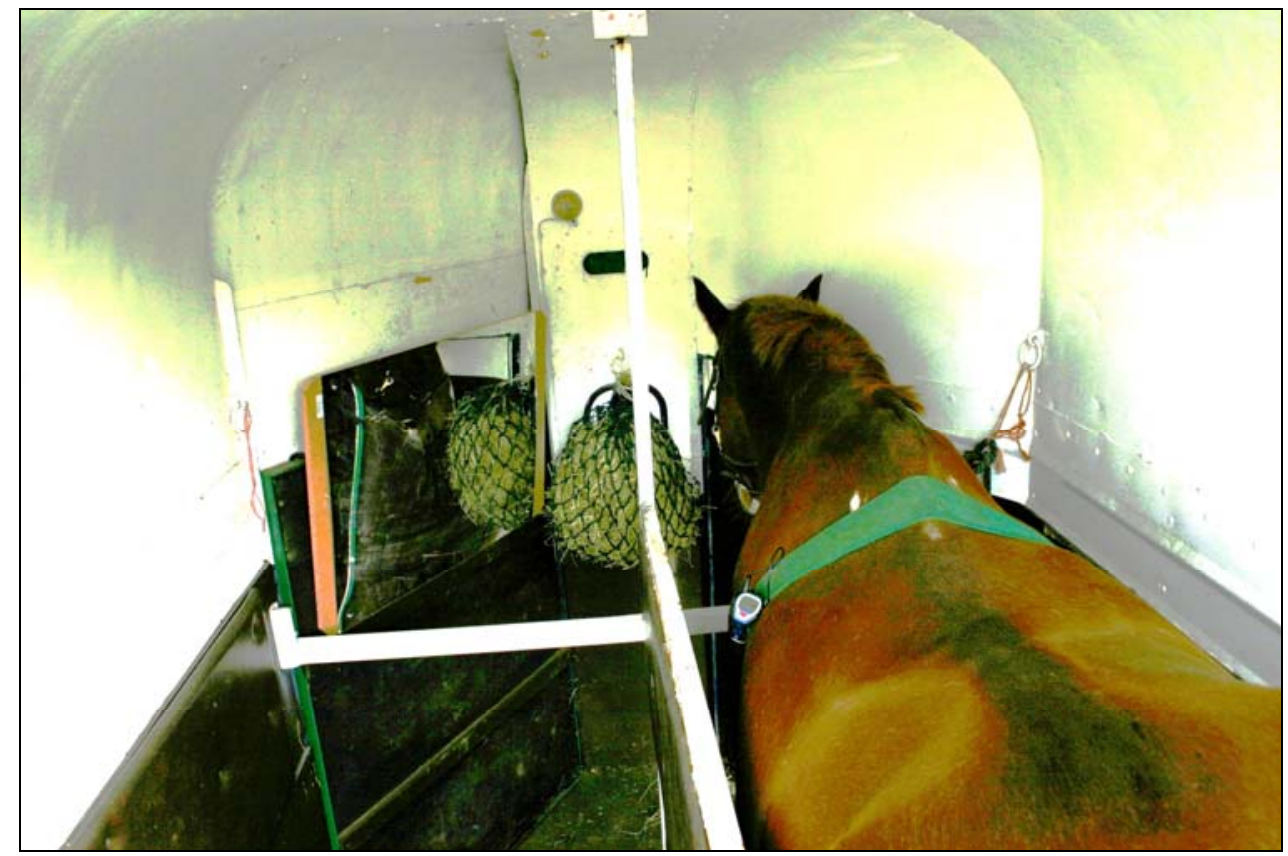

Figure 1: A test horse in position on the right-hand side of the trailer. Also shows position of mirror.

The journey undertaken was approximately thirty minutes in duration, 6.2 miles along minor roads that consisted of a number of bends and a slight incline but no hills. The same driver, experienced in towing horses, was used throughout the study. All of the trials were carried out during the month of August. Each horse was allowed at least 48 hours between each of the three treatments, and the order of treatment was counterbalanced to control for order effects (Table 3).

Table 3: Order of treatment - presentation of each condition was counterbalanced between subjects to control for order effects. The day of the 21-day trial during which each treatment was carried out is denoted in brackets.

\begin{tabular}{llll}
\hline Horse & Treatment 1 & Treatment 2 & Treatment 3 \\
\hline $\mathbf{1 - 4}$ & Mirror (1) & Companion (4) & Alone (7) \\
$\mathbf{5 - 8}$ & Companion (8) & Alone (11) & Mirror (14) \\
$\mathbf{9 - 1 2}$ & Alone (15) & Mirror (18) & Companion (21) \\
\hline
\end{tabular}




\subsection{Experimental Protocol}

On the morning of the experiment the test horse was brought in from the field to a stable, where ad libitum hay and water were available. The horse was fitted with the heart rate monitor (Polar Horse Trainer s610 ${ }^{\mathrm{TM}}$ ) and two electrode attachments held under an elastic surcingle. In the first instance, after a twenty minute period to allow the horse to settle, baseline measurements of $H R, T_{r}$ (using a Raytec ${ }^{\circledR}$ Laser Thermometer) and $T_{p}$ (using a NET-TEX Veterinary Digital Thermometer) were taken and recorded. To record $T_{p}$, the laser was pointed inside the ear-pinna and held for five seconds. The horse was then fitted with travel boots and tail guard and was walked a short distance from the stable and loaded onto the trailer.

Once loaded, the heart rate monitor and video recording were activated, and recordings of $T_{r}$ and $T_{p}$ were taken. On completion of the journey, the heart rate monitor and video recorder were stopped, and final recordings of $T_{p}$ and $T_{r}$ were noted. The horse was then unloaded and returned briefly to the stable where the heart rate monitor and travel equipment were removed, before being returned to the field.

During playback of the video recording, the duration of behavioural states was noted using a digital stopwatch for each occurrence. Heart rate readings were manually downloaded from the receiver, which was set to $\log \mathrm{HR}$ at sixty second intervals.

\subsection{Analysis of data}

Data were analysed using SPSS (version 12.0), a Kolmogorov-Smirnov normality test identified the pattern of distribution for each of the following data: duration of each behaviour; mean heart rates; change in rectal temperature before and after each treatment; change in ear-pinna temperature before and after each treatment. Vocalisation, head turning, pawing, head tossing and $\mathrm{T}_{\mathrm{p}}$ data were all abnormally distributed, therefore the non-parametric Kruskal-Wallis test was used. Eating, heart rate and $T_{r}$ data were found to be normally distributed, and so the parametric test, one-way ANOVA, was applied. Where a statistically significant result was obtained, further analysis was 
carried out via a General Linear Model post-hoc comparison test (Bonferroni) to determine which treatment produced a significant result.

\section{Results}

\subsection{Behaviour}

Compared with travelling alone, provision of the mirror significantly reduced the duration of vocalisation $(V)(p<0.05)$, head tossing $(\mathrm{HT})(\mathrm{p}<0.05)$, head turning $(\mathrm{TH})(\mathrm{p}<0.01)$, and increased eating (E) behaviour $(\mathrm{p}<0.05)$. Travelling with a live companion significantly reduced the duration of V $(\mathrm{p}<0.001)$, TH $(\mathrm{p}<0.001)$ HT $(\mathrm{p}<0.01)$ and pawing $(\mathrm{P})(\mathrm{p}<0.01)$, and increased E behaviour $(\mathrm{p}<0.05)$ was observed when compared to travel alone (Figure 2). No significant differences in behaviour were recorded during transportation between the mirror and companion other than $\mathrm{TH}$ behaviour which was significantly reduced with the companion $(\mathrm{p}<0.05)$.

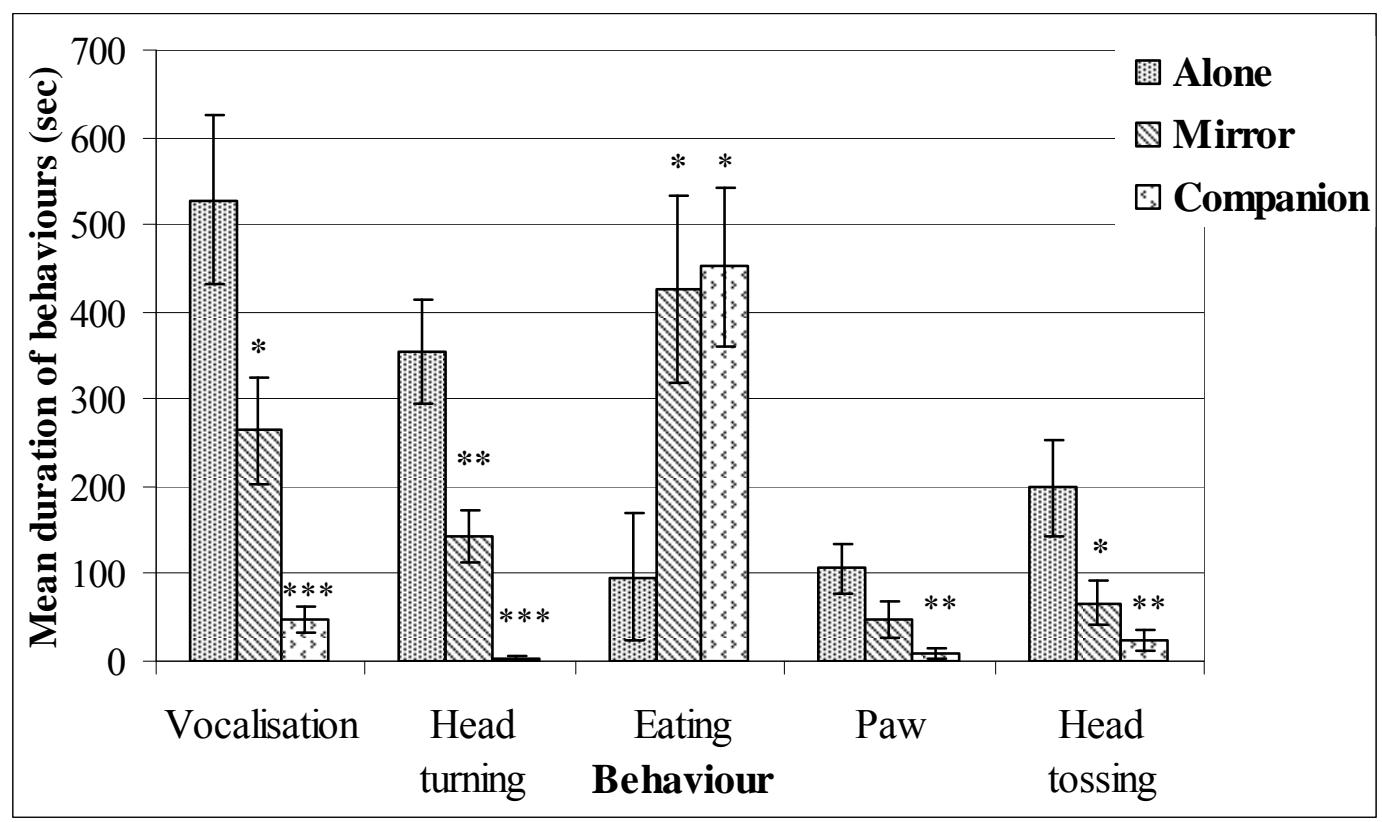

Figure 2: Mean duration of behaviours recorded per treatment. General Linear Model post-hoc comparison test (Bonferroni) * $\mathrm{p}<0.05 ; * * \mathrm{p}<0.01$; *** $\mathrm{p}<0.001$ when data compared with 'travelling alone'. 


\subsection{Heart rate}

The highest peak heart rates for all twelve horses (mean $88 \mathrm{bpm} \pm 5.32 \mathrm{SD}$ ), were recorded while travelling alone, during the third $(n=2)$, fourth $(n=7)$ and fifth minute $(n=3)$ of each journey.

Heart rates were consistently higher when travelling alone (mean $75 \mathrm{bpm} \pm 4.29 \mathrm{SD}$ ) than those recorded with the mirror (mean $70 \mathrm{bpm} \pm 5.64 \mathrm{SD}$ ), and with a companion (mean $67 \mathrm{bpm} \pm 5.51 \mathrm{SD}$ ) (Figure 3). However, only the presence of the companion caused a significant reduction in HR compared to travelling alone $(\mathrm{p}<0.01)$, travelling with the mirror did reduce heart rates but not at statistically significant levels.

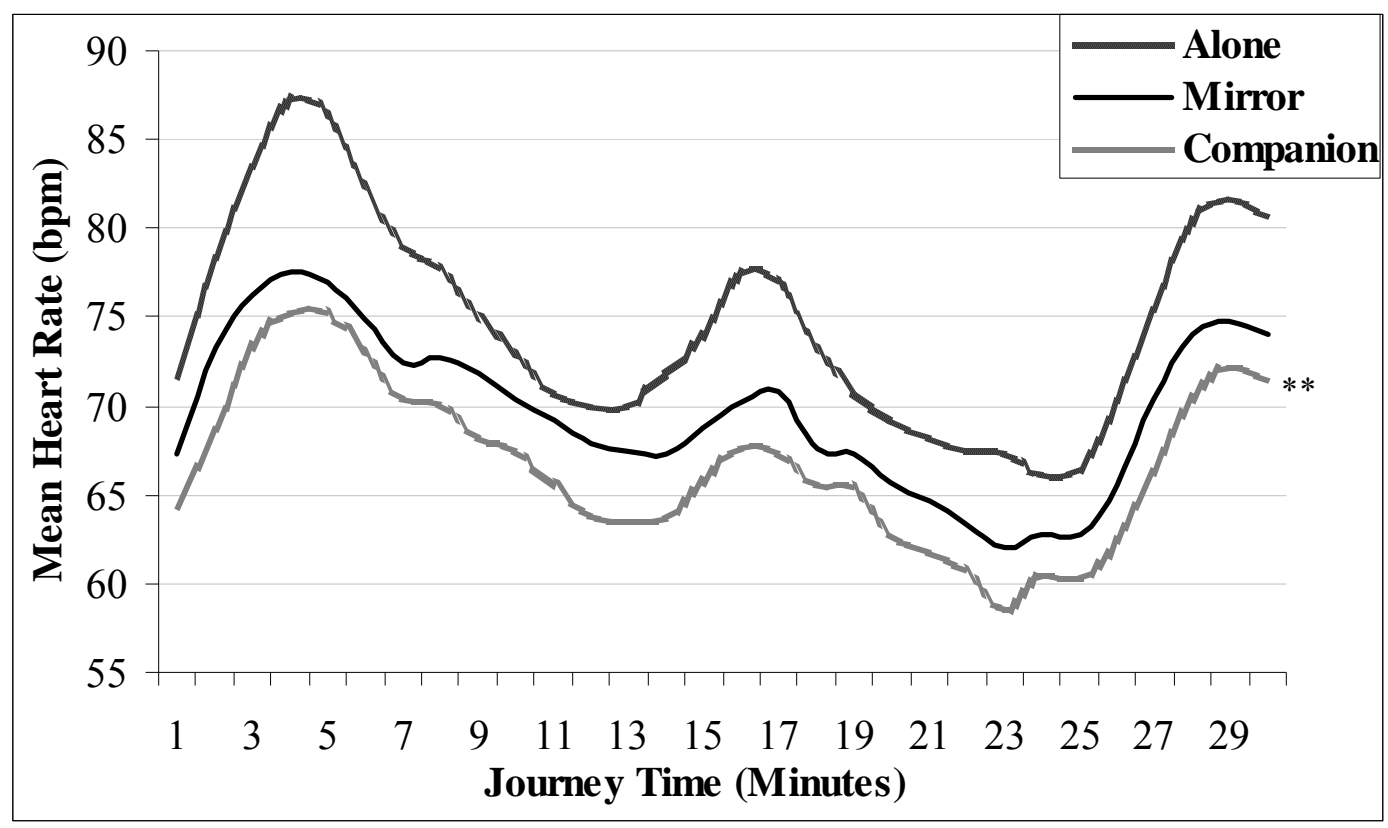

Figure 3: Mean heart rates recorded per treatment. General Linear Model post-hoc comparison test (Bonferroni) $* * \mathrm{p}<0.01$ when data compared with 'travelling alone'.

\subsection{Rectal temperature}

$\mathrm{T}_{\mathrm{r}}$ remained within the normal equine range of $37-38^{\circ} \mathrm{C}$ (Bennett and Hoffmann, 1999). A difference was seen in mean $\mathrm{T}_{\mathrm{r}}$ before and after each treatment, between each treatment and when compared with baseline $\mathrm{T}_{\mathrm{r}}$ (Figure 4). After transportation alone, mean $\mathrm{T}_{\mathrm{r}}$ increased for all 12 horses by $0.3^{\circ} \mathrm{C}( \pm 0.11 \mathrm{SD})$ to $38.1^{\circ} \mathrm{C}( \pm 0.25 \mathrm{SD})$. 


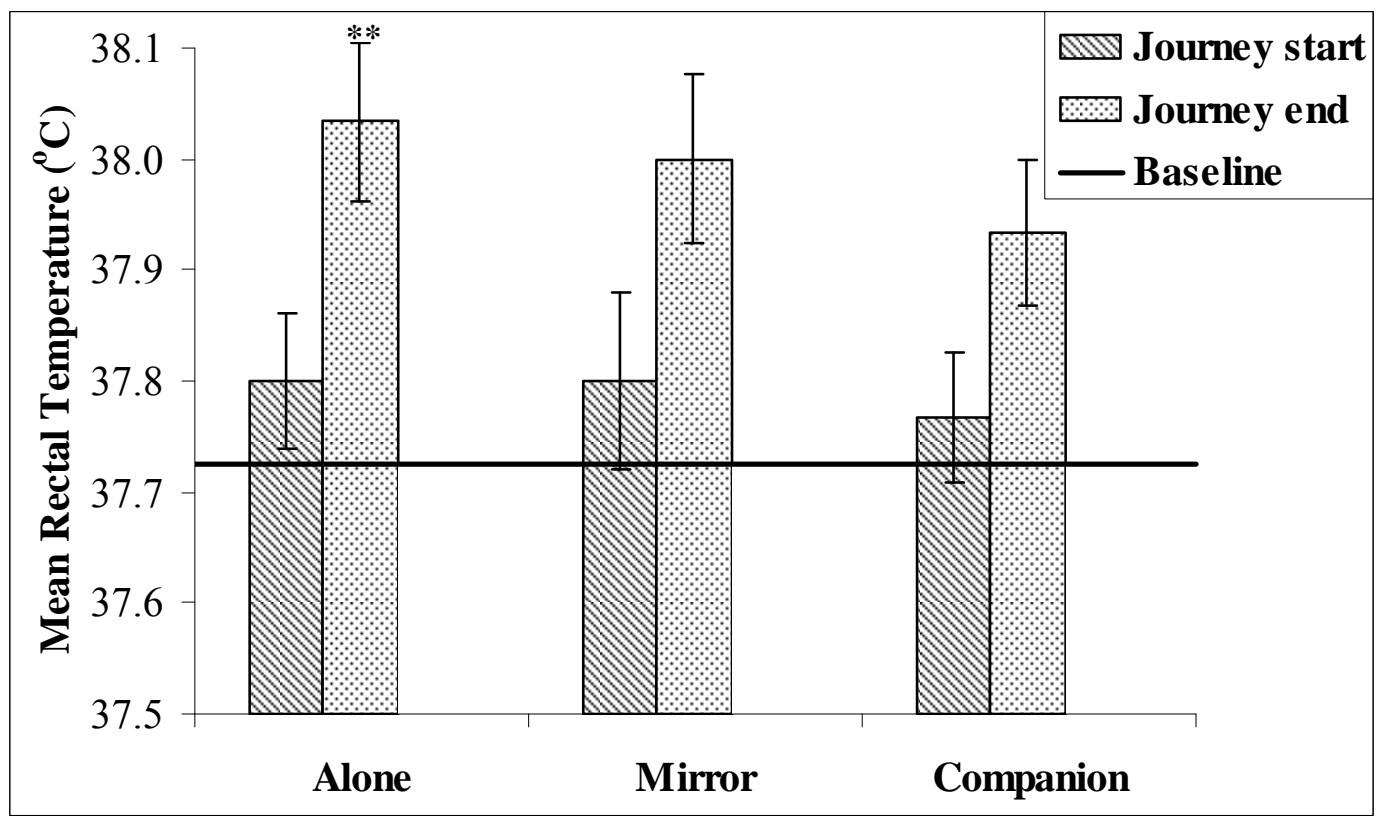

Figure 4: Mean rectal temperature measurements recorded per treatment. General Linear Model post-hoc comparison test (Bonferroni) $* * \mathrm{p}<0.01$.

Data analysis revealed that a significantly greater increase in $T_{r}$ was observed after travelling alone compared with the companion $(\mathrm{p}<0.01)$. While there was a greater increase in $\mathrm{T}_{\mathrm{r}}$ after travelling alone compared to the mirror, this did not reach significance at the $5 \%$ level $(\mathrm{p}=0.052)$ but does indicate a trend. No significant difference was recorded after travel with the mirror versus the companion.

\subsection{Ear-pinna temperature}

For both baseline and experimental measurements a wide range in $T_{p}\left(18.2-29.6^{\circ} \mathrm{C}\right)$ were recorded (Figure 5). After transportation alone, mean $\mathrm{T}_{\mathrm{p}}$ decreased for all 12 horses by $2.5^{\circ} \mathrm{C}( \pm 1.0 \mathrm{SD})$ to $21.9^{\circ} \mathrm{C}( \pm 1.7 \mathrm{SD})$. 


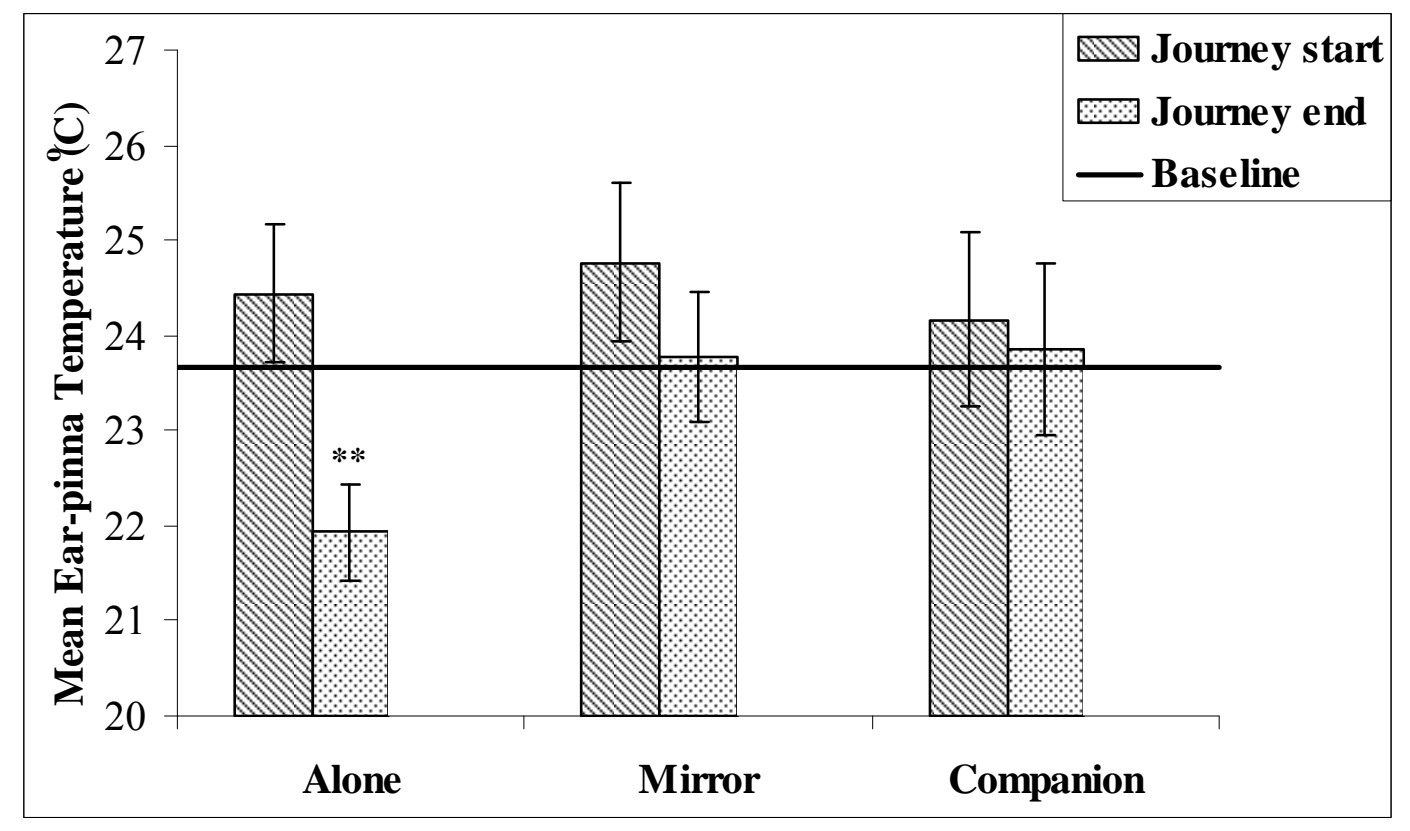

Figure 5: Mean ear-pinna temperature measurements recorded per treatment. General Linear Model post-hoc comparison test (Bonferroni) $* * \mathrm{p}<0.01$.

A significantly greater decrease in $T_{p}$ was recorded after travelling alone compared with the companion $(\mathrm{p}<0.01)$. While there was a greater decrease in $\mathrm{T}_{\mathrm{p}}$ after travelling alone compared to the mirror, this did not reach significance at the $5 \%$ level $(\mathrm{p}=0.051)$ but indicates a strong trend. No significant difference was recorded after travel with the mirror versus the companion.

\section{Discussion}

As horses are highly social animals, most will travel better with another horse but in reality this is not always practical, particularly for the single-horse owner. This study investigated whether placing a commercially available travel mirror in a trailer would cause a reduction in isolationrelated stress response by imitating visual contact with a live companion. Compared to travel alone, a significant reduction in the duration of vocalisation, head turning, and head tossing and an increase in eating behaviour was observed during transportation with both the mirror and live companion. Compared with travelling alone, travel with a live companion also gave rise to a 
significant reduction in the duration of pawing behaviour and mean heart rate, and both the increase in $T_{r}$ and fall in $T_{p}$ were significantly minimised, travel with the mirror achieved similar effects although these were not significant.

It is hypothesised that by placing a mirror in the trailer, the horse no longer feels isolated. Data from other studies investigating the use of mirrors as surrogate companionship suggest that the mirror may mimic visual contact with conspecifics (minimising social isolation) and/or provide environmental distraction or additional visual stimuli thereby altering the animals perception to the environment and their resultant responses to it (Parrott et al., 1988; Piller et al., 1999; Mills and Davenport, 2002; McAfee et al., 2002). There is also no evidence to suggest whether or not the horse is aware that the mirror reflection is their own, nor is it known if they view their reflection as a reasonable representation of a conspecific, since the mirror-image is devoid of appropriate olfactory, gustatory, vocal, and tactile signals.

Horses are known to emit a variety of vocalisations as well as other sounds that serve as communication within the herd and play an important role in maintaining group cohesion (Houpt, 1998; McDonnell, 2003). Vocal communication as observed in this experiment can be considered an intraspecific request for contact or recognition, and was the only behavioural activity to be displayed by all 12 horses for all three treatments; the duration of which was significantly longer when horses travelled alone. Turning head behaviour was often accompanied by vocalisation - the horses appeared to turn and call out as though searching for another horse, an activity previously observed in isolated horses (Jezierski and Gorecka, 1999; 2000). This is unsurprising as horses usually maintain visual contact with others for social cohesion (Kiley-Worthington and WoodGush, 1987; McDonnell, 2003). Although this may not cause concern initially, the horse is clearly not settled in the trailer and could become unbalanced if the head is not positioned centrally, which may lead to bruising from restraints/partitions, and even scrambling or falling.

Head tossing behaviour defined as wringing of the head and neck, and/or throwing the head up and down, was observed infrequently. Although this is not a specifically dangerous or disturbing 
behaviour it does indicate that the horse is ill at ease whilst in transit and, as a muscular activity, will increase heart rate and therefore energy expenditure. Travelling alone significantly increased the duration of vocalisation, head turning, and head tossing behaviour. Significantly more head turning behaviour was observed while travelling with the mirror than the companion $(p<0.05)$, but there may have simply been insufficient room to turn the head round with two horses inside the trailer. No other significant behavioural differences were recorded between the mirror and companion, indicating that horses responded similarly to both conditions.

Pawing is believed to be a displacement activity and commonly occurs in horses that have barrier frustration and are seeking to escape from their stalls, when restrained from moving, or in order to reach another horse (Ödberg, 1973, cited in Houpt, 1998), and has been linked to isolation stress in both sheep and horses (Abdel-Rahman, 2000; Jezierski and Gorecka, 1999; 2000). Only horses travelling with a companion showed significantly less pawing behaviour than when travelling alone, the mirror having no significant effect. This activity was infrequent compared to other behaviours, and tended to be carried out when the trailer came to a halt. When in motion all four feet needed to remain on the ground for balance preservation, leaving the horse no opportunity to lift a foreleg. Although pawing is a relatively safe activity while the trailer is stationary if performed excessively could result in leg/hoof injury or damage to the vehicle floor, and loss of balance is likely if an attempt was made at pawing whilst under motion. Standing still when the motion of transport had ceased would prevent unnecessary elevation of the heart rate as pawing involves muscular activity. Smith et al. (1996) found that following 24-hours of road transportation, in addition to haematological changes horses had decreased body weights indicating slight dehydration. Water and hay intake rates were also significantly lower during transport than pre-transport. Nontransport studies using isolated sheep and horses have observed a reduction in time spent eating when visual contact is prevented (Sweeting et al., 1985; Houpt and Houpt, 1992; Abdel-Rahman, 2000; Strand et al., 2002). In this experiment time spent eating was significantly reduced when travelling alone than with the mirror or companion, supporting the findings of Sweeting et al. 
(1985) that horses eat when other horses eat and eat more if they can see another horse eating, and potentially indicating that the mirror may have been interpreted by the horses as a companion. Correlation analysis confirmed that an inverse relationship existed between eating behaviour and all other anxiety related behaviour. Although this was apparent regardless of treatment the strongest relationship was observed during travel alone (-0.21 to -0.67$)$. Remaining still and quiet during travel provided increased opportunity for the horse to eat (as it is significantly less likely to eat whilst simultaneously vocalising, turning head, shaking the head or pawing). On longer journeys, a reduction in feeding behaviour when travelling alone, coupled with other negative behaviours and elevated heart rates could cause weight loss and fatigue which may prove deleterious to performance, or even a welfare concern.

It is well known that transportation can cause both tachycardia and hormonal disruption in horses (Baucus et al., 1990; Clark et al., 1993; Warren and Cuddeford, 1995; Stull and Rodiek, 2000, 2002; Stull et al., 2004). Previous studies have confirmed cardiac frequency monitoring as a valuable measure of the immunological condition (Harlow et al.,1987), energy expenditure (Giovagnoli et al., 2002), and welfare for short term stressors such as those encountered during loading and transport (Minero et al., 2001; Broom et al., 2002; Honkavaara et al., 2003).

An association was observed between heart rate response and the stage of the journey; regardless of treatment, heart rates tended to follow a similar pattern, peaking around minute 4,17 and 29 , and falling around minute 12 and 23 of the journey. This was expected, as the first and last five minutes of the experiment coincided with travel over uneven ground and passed field companions of the test horses. Around minutes 12 and 23, travel was along a smooth, straight road that would account for reduced heart rates. Heart rate then peaked again mid-journey around the point at which the trailer halted at a road junction, probably due to increased anxiety or anticipation.

Only travel with the companion caused a significant reduction in mean HR compared to travel alone $(p<0.01)$. These findings concur with Jezierski and Gorecka $(1999,2000)$ who noted significant increases in the heart rate of horses during isolation, and Piller et al. (1999) who recorded reduced 
heart rates in isolated heifers exposed to a mirror image. A study on transported horses by Giovagnoli et al. (2002) reported that muscle activity and heart rate are very closely correlated.

As part of the cardiovascular response to a defence-alarm reaction it was hypothesised that a fall in $T_{p}$ and rise in $T_{r}$ would be observed due to the vasoconstriction of non-critical organs and skin, and vasodilation in working skeletal muscle which helps to ensure adequate blood flow for the critical organs. Previous studies using sheep have investigated the effects of exposure to isolation and transport stressors on peripheral body temperatures and found an inverse relationship between $T_{r}$ and $T_{p}$ (Ingram et al., 2002; Lowe et al. 2005). If decreases in $T_{p}$ can be used to indicate vasoconstriction, it may therefore be possible to use changes in $T_{p}$ as a measure of the defence reaction.

Whilst remaining within the normal equine rectal temperature range of $37.5^{\circ} \mathrm{C}$ to $38.5^{\circ} \mathrm{C}$, a greater increase in mean $T_{r}$ was recorded after travel alone, than with the companion $(p<0.01)$. Although a greater increase in $\mathrm{T}_{\mathrm{r}}$ was recorded after travelling alone compared with the mirror, this did not reach significance at the $5 \%$ level $(\mathrm{p}=0.052)$ but does indicate a very strong trend. Although all 12 horses had increased $T_{\mathrm{r}}$ recorded after being transported alone, not all treatments produced this response; two horses had a reduction in $\mathrm{T}_{\mathrm{r}}$ after travel with the mirror and one horse recorded no change in $\mathrm{T}_{\mathrm{r}}$ after travelling with a companion.

The normal temperature range for the Equine ear-pinna is unknown and a wide range in $T_{p}$ was recorded for both baseline and experimental measurements. However, a greater decrease in mean $T_{p}$ was recorded after travel alone, than with the companion $(p<0.01)$. Concurrent with rectal temperature data despite a greater decrease in $\mathrm{T}_{\mathrm{p}}$ after travelling alone compared to travelling with a mirror, this did not reach significance at the $5 \%$ level $(\mathrm{p}=0.051)$ but again indicates a very strong trend. Although all 12 horses had a decrease in $\mathrm{T}_{\mathrm{p}}$ recorded after transportation alone, not all treatments yielded this result; three horses had an increase in $T_{p}$ after transportation with the mirror and two horses recorded an increase $\mathrm{T}_{\mathrm{p}}$ after transportation with a companion. No significant difference was found between either $T_{r}$ or $T_{p}$ data when travel with the mirror and companion was 
compared, confirming that the horses reacted similarly during both these treatments. Correlation analysis confirmed that a positive relationship existed between $T_{r}$ and $H R(0.3)$, and negative relationship between $T_{p}$ and HR regardless of treatment (-0.2).

These results indicate that the defence-alarm reaction in horses may involve vasoconstriction and subsequent decrease in $\mathrm{T}_{\mathrm{p}}$, concurrent with an increase in core temperature, and could potentially form the basis for subsequent investigation into the measurement of peripheral blood flow as an indicator of acute stress in the horse. However, as a wide range of $T_{p}$ were recorded for both baseline and experimental measurements, and with great variability between horses, further experimental work is recommended in order to refine both procedure and technique and to verify these preliminary results.

\section{Conclusion}

This experiment demonstrates that isolation during transportation in a trailer can be associated with behavioural and physiological signs of stress; it is therefore recommended that horses are transported with a live companion, but if none is available, a surrogate companion in the form of a travel mirror is preferable to travelling alone.

\section{References}

Abdel-Rahman, M. A., 2000. Behavioural and endocrinological changes of sheep subjected to isolation stress. Assiut Veterinary Medical Journal. 42 (84) 1-12

Alexander, S. L., Irvine, C. H. G., Livesey, J. H., Donald, R. A., 1988. Effect of isolation stress on concentrations of arginine vasopressin, $\alpha$-melanocyte-stimulating hormone and ACTH in the pituitary venous effluent of the normal horse. Journal of Endocrinology. 116 (3) 325-334 
Baldock, N. M., Sibly, R. M., 1990. Effects of handling and transportation on the heart rate and behaviour of sheep. Applied Animal Behaviour Science. 28 (1-2) 15-39

Baucus, K. L., Ralston, S. L., Nockels, C.F., McKinnon, O. A., Squires, E. L., 1990. Effects of Transportation on early embryonic death in mares. Journal of Animal Science. 68, 345-351.

Bennett, D., Hoffmann, R. S., 1999. Equus Caballus. Mammalian Species. 628, 1-14.

Broom, D. M., Barton-Gade, P., Ferlazzo, A., Hartung, J., Manteca, X., Warriss, P., 2002. The welfare of animals during transport (details for horses, pigs, pigs, sheep and cattle). European Commisson Report of the Scientific Committee on Animal Health and Animal Welfare.

Clark, D. K., Friend, T. H., Dellmeir. G., 1993. The effect of orientation during trailer transport on heart rate, cortisol and balance in horses. Applied Animal Behaviour Science. 38, 179-189.

Cregier, S. E., 1982. Reducing equine hauling stress: A review. Equine Veterinary Science. November/December p187-198

Friend, T. H., 2001. A review of recent research on the transportation of horses. Journal of Animal Science. 79 (E. Suppl.) E:32-E40

Giovagnoli, G., Marinucci, M. T., Bolla, A., Borghese, A., 2002. Transport stress in horses: an electromyographic study on balance preservation. Livestock Production Science. 73 (2-3) 247-254.

Harlow, H. J., Thorn, E. T., Williams, E. S., Belden, E. L., Gern, W. A., 1987. Cardiac frequency: a potential predictor of blood cortisol levels during acute and chronic stress exposure in Rocky 
Mountain bighorn sheep (Ovis canadensis canadensis). Canadian Journal of Zoology. 65 (8) 20282034 (Abstract only).

Honkavaara, M., Rintasalo, E., Ylonen, J., Pudas, T., 2003. Meat quality and transport stress of cattle. Deutsche Tierarztliche Wochenschrift. 110 (3) 125-128 (Abstract only).

Houpt, K. A., Houpt, T. R., 1992. Social and illumination preferences of mares. Equine Practice. 14 (6) 11-16.

Houpt, K. A., 1998. Domestic Animal Behaviour for Veterinarians and Animal Scientists $\left(3^{\text {rd }}\right.$ Edition). Manson Publishing, London.

Ingram, J. R., Cook, C. J., Harris, P. J., 2002. The effect of transport on core and peripheral body temperatures and heart rate of sheep. Animal Welfare. 11 (1) 103-112.

Jezierski, T., Gorecka, A., 1999. Relationship between behavioural reactions and heart rate in horses during transient social isolation. Animal Science Papers and Reports. Polish Academy of Sciences, Institute of Genetics and Animal Breeding. 17 (3) 101-114

Jezierski, T., Gorecka, A., 2000. Changes in the horses heart rate during different levels of social isolation. Animal Science Papers and Reports. Polish Academy of Sciences, Institute of Genetics and Animal Breeding. 18 (1) 33-41

Kiley-Worthington, M., Wood-Gush, D., 1987. Stereotypic behaviour. In: N. E. Robinson (ed) Current Therapy in Equine Medicine (Vol II). W. B. Saunders, USA. p131-134. 
Leadon, D. P., 1995. Transport stress and the equine athlete. Equine Veterinary Education. 7 (5) 253-255.

Lee, J., Houpt, K., 2001. A survey of trailering problems in horses. Journal of Equine Veterinary Science. 21 (5) 237-241

Lowe, T. E., Cook, C. J., Ingram, J. R., Harris, P. J., 2005. Changes in ear-pinna temperature as a useful measure of stress in sheep (Ovis aries). Animal Welfare. 14, 35-42.

McAfee, L. M., Mills, D. S., Cooper, J. J., 2002. The use of mirrors for the control of stereotypic weaving behaviour in the stabled horse. Applied Animal Behaviour Science. 78 (2-4) 159-173.

McDonnell, S., 2003. The Equid Ethogram. The Blood-Horse Inc. Kentucky. USA.

Mills, D. S., Davenport, K., 2002. The effect of a neighbouring conspecific versus the use of a mirror for the control of stereotypic weaving behaviour in the stabled horse. Animal Science. 74 (1) 95-101.

Minero, M., Canali, E., Ferrante, V., Carenzi, C., 2001. Measurement and time domain analysis of heart rate variability in dairy cattle. Veterinary Record. 149 (25) 772-774.

Oikawa, M., Takagi, S., Anzai, R., Yoshikawa, H., Yoshikawa, T., 1995. Pathology of equine respiratory disease occurring in association with transport. Journal of Comparative Pathology. 113 (1) $29-43$. 
Parrott, R. F., Houpt, K. A., Misson, B. H., 1988. Modification of the responses of sheep to isolation stress by the use of mirror panels. Appl. Anim. Behav. Sci. 19: 331-338.

Piller, C. A. K., Stookey, J. M., Watts, J. M., 1999. Effects of mirror-image exposure on heart rate and movement of isolated heifers. Applied Animal Behaviour Science. 63 (2) 93-102.

Smith, B. L., Jones, J. H., Hornof, W. J., Miles, J. A., Longworth, K. E., Willits, N. H. 1996. Effects of road transport on indices of stress in horses. Equine Veterinary Journal. 28 (6) 446-454.

Strand, S. C., Tiefenbacher, S., Haskell, M., Hosmer, T., McDonnell, S. M., Freeman, D. A., 2002. Behavior and physiologic responses of mares to short-term isolation. Applied Animal Behaviour Science. 78 (2-4) 145-157.

Stull, C. L., Rodiek, A. V., 2000. Physiological responses of horses to 24 hours of transportation using a commercial van during summer conditions. Journal of Animal Science. 78, 1458-1466.

Stull, C. L., Rodiek, A. V., 2002. Effects of cross-tying horses during 24 h of road transport. Equine Veterinary Journal. 34 (6) 550-555.

Stull, C. L., Spier, S. J., Aldridge, B. M., Blanchard, M., Stott, J. L., 2004. Immunological response to long-term transport stress in mature horses and effects of adaptogenic dietary supplementation as an immunomodulator. Equine Veterinary Journal. 36 (7) 583-589.

Sweeting, M. P., Houpt, C. E., Houpt, K. A., 1985. Social facilitation of feeding and time budgets in stabled ponies. Journal of Animal Science. 60 (2) 369-374. 
Traub-Dargatz, J. L., McKinnon, A. O., Bruyninckx, W. J., Thrall, M. A., Jones, R. L., Blancquaert, A. M., 1988. Effect of transport stress on bronchoalveolar lavage fluid analysis in female horses. American Journal of Veterinary Research. 49, 1026-1029 (Abstract only).

Waran, N. K., Cuddeford, D., 1995. Effects of loading and transport on the heart rate and behaviour of horses. Applied Animal Behaviour Science. 43, 71-81. 